\title{
Association Between Serum Lactate Level During Cardiopulmonary Resuscitation and Survival in Adult Out-of- Hospital Cardiac Arrest: A Multicenter Cohort Study (The Critical Study in Osaka, Japan)
}

Norihiro Nishioka

Kyoto Daigaku https://orcid.org/0000-0001-5218-9819

Daisuke Kobayashi ( $\square$ kobayashi.daisuke.2e@kyoto-u.ac.jp )

https://orcid.org/0000-0001-6194-9453

Junichi Izawa

Okinawa Prefectural Yaeyama Hospital

Taro Irisawa

Osaka Daigaku Igakubu Fuzoku Byoin Kodo Kyumei Kyukyu Center

Tomoki Yamada

Osaka Police Hospital

Kazuhisa Yoshiya

Kansai Ika Daigaku Fuzoku Takii Byoin

Changhwi Park

Tane General Hospital

Tetsuro Nishimura

Osaka Shiritsu Daigaku

Takuya Ishibe

Kinki Daigaku Igakubu Daigaku Byoin

Yoshiki Yagi

Koeki Zaidan Hojin Osaka-fu Mishima Kyumei Kyukyu Center Toshoshitsu

Takeyuki Kiguchi

Osaka General Medical Center

Masafumi Kishimoto

Osaka Prefectural Nakakawachi Medical center

Toshiya Inoue

Senshu Trauma and Critical Care center

Yasuyuki Hayashi

Saiseikai Senri Hospital

Taku Sogabe

Kokuritsu Byoin Kiko Osaka Iryo Center

Takaya Morooka

Osaka Shiritsu Sogo Iryo Center

Haruko Sakamoto

Osaka Sekijuji Byoin

Keitaro Suzuki

Kishiwada Tokushukai Byoin

Fumiko Nakamura

Kansai Ika Daigaku

Tasuku Matsuyama 
Kyoto Furitsu Ika Daigaku

Yohei Okada

Kyoto Daigaku

Satoshi Matsui

Osaka Daigaku

Atsushi Hirayama

Osaka Daigaku

Satoshi Yoshimura

Kyoto Daigaku

Shunsuke Kimata

Kyoto Daigaku

Takeshi Shimazu

Osaka Daigaku Igakubu Fuzoku Byoin Kodo Kyumei Kyukyu Center

Tetsuhisa Kitamura

Osaka Daigaku

Takashi Kawamura

Kyoto Daigaku

Taku Iwami

Kyoto Daigaku

Original research

Keywords: Out-of-hospital cardiac arrest, Lactate, Early prognostication, Cardiopulmonary resuscitation

Posted Date: July 8th, 2020

DOI: https://doi.org/10.21203/rs.3.rs-40098/v1

License: @ (i) This work is licensed under a Creative Commons Attribution 4.0 International License. Read Full License 


\section{Abstract}

Background:

Serum lactate reflects hypoxic insult in many conditions, but its role as prognostic markers after cardiac arrest is still controversial. This study aimed to investigate the association between serum lactate levels during cardiopulmonary resuscitation (CPR) and survival in patients with out-of-hospital cardiac arrest (OHCA).

\section{Methods:}

We analyzed the data of the Osaka Comprehensive Registry of Intensive Care for OHCA Survival (CRITICAL) study, a prospective multicenter observational study of 14 participating institutions in Osaka Prefecture, Japan that enrolled consecutive OHCA patients. We included adult nontraumatic OHCA patients transported to the hospital with ongoing CPR from 2013 to 2017. Based on the serum lactate levels during CPR, the patients were divided into four quartiles: Q1 (lactate $\leq 10.6 \mathrm{mEq} / \mathrm{L}), \mathrm{Q} 2(10.6<$ lactate $\leq 14.1 \mathrm{mEq} / \mathrm{L})$, Q3 $(14.1<$ lactate $\leq 18.0 \mathrm{mEq} / \mathrm{L})$, and Q4 (lactate $>18.0 \mathrm{mEq} / \mathrm{L})$. The primary outcome of this study was 1-month survival.

\section{Results:}

A total of 11,960 patients were registered and 4,978 of them were eligible for our analyses. The Q1 group had the highest 1-month survival $(4.3 \%[53 / 1,245])$, followed by Q2 $(2.5 \%$ [31/1,245]), Q3 $(1.1 \%[14 / 1,328])$, and Q4 $(0.5 \%[6 / 1,160])$ groups. In the multivariable logistic regression analysis, the proportion of 1-month survival in the Q4 group was significantly lower than that in the Q1 group (adjusted odds ratio $0.21 ; 95 \%$ confidence interval 0.086 to 0.50 ). One-month survival decreased in a stepwise manner as the quartiles increased ( $p$ for trend $<0.001$ ). In subgroup analysis, there was a significant interaction between initial rhythm and survival ( $p$ for interaction $<0.001$ ); 1-month survival of patients with a non-shockable rhythm decreased when the lactate levels increased ( $p$ for trend $<0.001$ ), but not in patients with a shockable rhythm ( $p$ for trend $=0.76$ ).

\section{CONCLUSION:}

High serum lactate level during CPR was associated with poor 1-month survival in OHCA patients. Serum lactate may be one of the effective prognostic indications for OHCA during CPR, especially in patients with non-shockable rhythm.

\section{Background}

Out-of-hospital cardiac arrest (OHCA) represents one of the serious public health concerns in industrialized countries, with approximately 350,000-700,000 deaths due to OHCA annually in the European Union, ${ }^{1} 400,000$ in the United States, ${ }^{2}$ and 120,000 in Japan. ${ }^{3}$ Recently, advanced interventions before the return of spontaneous circulation (ROSC), such as the implementation of extracorporeal cardiopulmonary resuscitation (ECPR) and target temperature management (TTM), have been attempted to improve the prognosis of cardiac arrest patietns. ${ }^{4,5}$ Nonetheless, it is not easy for emergency and/or intensive care physicians to decide whether to proceed to the advanced interventions during cardiopulmonary resuscitation (CPR) or to stop CPR during resuscitation efforts for OHCA patients who do not achieve ROSC.6,7 Therefore, a marker, which can be measured during CPR, can facilitate the decision-making process in the provision of intensive care for OHCA patients to improve their outcomes.

Lactate levels can be measured easily and quickly in clinical settings and represent a good marker of tissue hypoxia. ${ }^{8-10}$ Therefore, lactate levels can be measured to predict prognosis in critical illnesses such as sepsis, trauma, and burns. ${ }^{11-13}$ On the other hand, the relation between serum lactate levels in the early phase after ROSC and outcome of cardiac arrest patients has been controversial. ${ }^{15-}$

${ }^{19}$ Additionally, the usefulness of lactate levels during CPR without achieving ROSC in OHCA patient, as a predictor, has not been sufficiently evaluated.

Using a multicenter, prospective registry in Osaka, Japan, designed to accumulate both pre- and in-hospital information on treatments and laboratory data of OHCA patients, this study aimed to investigate the association between serum lactate levels during CPR and survival outcomes in OHCA patients who did not achieve ROSC in prehospital settings.

\section{Methods}


The present study was a secondary analysis of data from the Comprehensive Registry of Intensive Cares for OHCA Survival (the CRITICAL) study. The CRITICAL study is a multicenter prospective registry, designed to accumulate both the prehospital and the inhospital data on OHCA treatments, to understand the entire care process, and to improve outcomes after OHCA. A complete description of the study methodology can be found elsewhere. ${ }^{20}$ The CRITICAL study group consists of 16 tertiary emergency medical institutions including 15 Critical Care Medicine Centers (CCMCs) and 1 non-CCMC with a department of emergency treatments in Osaka Prefecture in Japan, which has an area of $1,905 \mathrm{~km}^{2}$ and had a residential population of about 8.8 million in 2017. Approximately 7,500 OHCA cases occur in Osaka Prefecture every year ${ }^{21}$ and nearly $30 \%$ of them are transported to the CCMCs. ${ }^{22}$ Therefore, over 2,000 OHCA patients have been registered every year, and the study is ongoing with an indefinite study period. The CRITICAL study registered consecutive patients suffering from OHCA, who were resuscitated by emergency medical services (EMS) and were transported to the participating hospitals. This registry excluded OHCA patients for whom CPR was not performed by the physicians after arrival at the hospital or whose family members refused to participate in the registry.

\section{Study Population}

In this study, we included adult patients aged $\geq 18$ years with OHCA with non-traumatic causes, who did not achieve ROSC before arrival at the hospital, and whose serum lactate levels during CPR at the hospital were measured during the study period from January 1, 2013 to December 31, 2017. We excluded OHCA patients who were treated by extracorporeal membrane oxygenation. This study protocol was approved by the Ethics Committee of Kyoto University and each participating hospital.

\section{The Emergency Medical Service System in Osaka Prefecture}

Anyone can call the 119 emergency services anywhere in Japan, and on receipt of the emergency call, a dispatch center sends the nearest available ambulance to the scene. Emergency services are accessible anytime. Each ambulance includes a three-person unit providing life support. They can insert an intravenous line and an adjunct airway and use a semi-automated external defibrillator for OHCA patients. Highly trained EMS personnel are called emergency life-saving technicians, who are allowed to provide shocks without consulting a physician, and specially trained emergency life-saving technicians are permitted to perform tracheal intubation to administer adrenaline to OHCA patients. Since EMS providers cannot generally accept do-not-resuscitate orders in Japan, they do not terminate resuscitation in the field. Therefore, the EMS personnel transports almost all OHCA patients, except cases of decapitation, incineration, decomposition, rigor mortis, or dependent cyanosis. All EMS providers perform CPR according to the Japanese CPR guidelines. ${ }^{23}$ Previous reports have illustrated details of the EMS system in Japan. ${ }^{24,25}$

\section{Prehospital and In-hospital Measurements}

We obtained anonymized prehospital resuscitation data from the All-Japan Utstein Registry of the Fire and Disaster Management Agency (FDMA). Details of the registry have been described in previous papers. ${ }^{2}, 26$ Data were collected prospectively using the data form of the Utstein-style international guideline of reporting OHCA. ${ }^{27}$ The following data were collected: witness status, bystanderinitiated CPR, shock delivery by public-access automated external defibrillators, dispatcher instructions, first documented rhythm on the EMS arrival, advanced airway management, adrenalin administration, and resuscitation time courses. A data form was completed by the physician in charge of the patient or medical staff in cooperation with the physician. Data were uploaded into the registry system on the FDMA database server, checked logically by the computer system, and confirmed by the implementation working group. If a data form was incomplete, the FDMA returned it to the specific fire station for completion.

In this registry, detailed data were prospectively collected for consecutive patients with OHCA after they arrived at the hospital. Anonymized data were entered into a web form by the physician or medical staff in cooperation with the physician in charge of the patient, checked logically by the computer system, and confirmed by the CRITICAL study working group. If a data form was incomplete, the working group returned it to the specific institution for completion. The working group combined the detailed inhospital data and the Utstein-style data from the FDMA on the web, based on five key variables of the emergency call: date, time, age, sex, and Glasgow-Pittsburgh cerebral performance category (CPC) present in both datasets.

In-hospital data of OHCA patients after arrival at the hospital were collected prospectively using the original report form: age, ROSC after hospital arrival, first documented rhythm at the hospital, laboratory data, actual detailed treatments for an OHCA patient (e.g., 
extracorporeal membrane oxygenation, coronary angiography, and TTM), causes of arrest, and outcome data. The causes of arrest were divided into cardiac and non-cardiac (cerebrovascular diseases, respiratory diseases, malignant tumors, and external causes, including traffic injury, fall, hanging, drowning, asphyxia, drug overdose, or any other external cause) origins. The diagnosis of cardiac or non-cardiac origin was made clinically by the physician in charge. Regarding the outcome data, 1-month survival and neurological status were prospectively collected.

\section{Outcomes}

The primary outcome of this study was 1-month survival. The secondary outcomes were any ROSC after hospital arrival and 30-day survival with a good neurological outcome, defined as CPC of 1 or 2 . We defined ROSC as a continuous palpable circulation with a self-beat for more than 30 seconds. ${ }^{27}$ The neurological status was evaluated using the CPC scale (category 1 , good cerebral performance; category 2, moderate cerebral disability; category 3, severe cerebral disability; category 4 , coma or vegetative state; category 5 , death/brain death) ${ }^{28}$

\section{Statistical Analysis}

In this study, we divided patients into quartiles based on the serum lactate levels with on-going CPR: Q1 (lactate $\leq 10.6 \mathrm{mmol} / \mathrm{L}$ ), Q2 $(10.6<$ lactate $\leq 14.1 \mathrm{mmol} / \mathrm{L})$, Q3 $(14.1<$ lactate $\leq 18.0 \mathrm{mmol} / \mathrm{L})$, and Q4 (lactate $>18.0 \mathrm{mmol} / \mathrm{L})$. We evaluated the patient characteristics between the four groups using Kruskal-Wallis tests for continuous variables and chi-square tests or Fisher exact tests for categorical variables. In addition, to determine the association between the lactate level quartiles and outcomes, we constructed univariable and multivariable logistic regression models and assessed crude and adjusted odds ratios (OR) and their 95\% confidence intervals (Cls). We adjusted for the potential confounders in the multivariable models that were biologically and clinically essential and considered to be associated with the outcomes, including age (continuous value), sex (men or women), witness status (yes or no), bystander CPR status (yes, no), first documented rhythm at the scene (shockable [ventricular fibrillation and pulseless ventricular tachycardia] or non-shockable [pulseless electrical activity and asystole]), prehospital adrenaline administration (yes or no), prehospital advanced airway management (yes or no), and time from the call to hospital arrival (continuous value). We did a complete case analysis with adjusted confounders. Additionally, we performed a receiver operating characteristics (ROC) curve analysis with an area under the curve of serum lactate levels before ROSC to predict 1-month survival in patients with OHCA. Moreover, we carried out a planned subgroup analysis stratified by the first documented rhythm at the scene (shockable or nonshockable). We assessed the interaction effect between lactate levels and first documented rhythm in 1-month survival in the multivariable logistic regression model. All P-values were two-tailed and 0.05 levels were considered statistically significant. All statistical analyses were conducted using R (The R Foundation for Statistical Computing, version 3.6.0) and EZR (Saitama Medical Center, Jichi Medical University, version 1.41, Saitama, Japan), which is a graphical user interface for R. ${ }^{29}$

\section{Results}

\section{Study Participants}

A total of 11,960 OHCA patients were documented during the study period. Of the 11,636 patients in whom resuscitation was attempted after arrival at the hospital, the data of 10,539 patients were combined with the prehospital data. Of them, we excluded 313 children aged $<18$ years, 1,536 patients with traumatic causes, 101 patients whose OHCA was witnessed by on-scene EMS personnel, 190 patients whose first documented rhythm was unknown, 881 patients who achieved ROSC in prehospital settings, 44 patients who presented the pulse at hospital arrival, and 440 patients treated by extracorporeal membrane oxygenation. Further excluding 1,380 patients without data on serum lactate data before ROSC, 636 patients without data on time to lactate measurement, and 40 patients with a negative time interval from measuring lactate to ROSC, a total of 4,978 OHCA patients who were admitted to the hospital without ROSC were finally eligible for our analyses (Figure 1).

The characteristics of patients divided by lactate level quartile are outlined in Table 1. In the Q1 group, the median age was higher than that in other groups. The Q1 group was more likely to have witnessed status, defibrillation by EMS, adrenaline administration by EMS, first documented shockable rhythm at the scene, shockable rhythm after hospital arrival, defibrillation at the hospital, coronary angiography, and TTM than other groups. Furthermore, the time from the call to arrival at the hospital was shorter in the Q1 than in the other quartiles, but the time from arrival at the hospital to measuring lactate was similar for all the groups. 
Overall, 1-month survival was $2.1 \%(104 / 4,978)$. The rates of 1-month survival decreased gradually from the first to the fourth quartile (Q1, 4.3\%; Q2, 2.5\%; Q3, 1.1\%; Q4, 0.5\% ( $p$ for trend < 0.001; Table 2). In the multivariable logistic regression analysis, 1-month survival in the highest quartile group was significantly lower than that in the lowest quartile group (adjusted OR $0.21 ; 95 \% \mathrm{Cl} 0.09-0.50$ ). The ROC curve showed the area under the curve of $0.70(95 \% \mathrm{Cl} 0.65-0.75)$. The proportion of favorable neurological outcomes showed a similar tendency as 1-month survival ( $p$ for trend $=0.048$ ). However, we could not investigate the neurological outcomes by multivariable analysis because of small number of survivors with a favorable neurological outcome after hospital arrival.

In the subgroup analyses stratified by the first documented rhythm (Table 3), 1-month survival of OHCA patients with non-shockable rhythm decreased when the lactate levels increased ( $p$ for trend $<0.001$ ), but in patients with shockable rhythm, this trend was not observed ( $p$ for trend $=0.574$ ). There was a significant interaction ( $p$ for interaction $<0.001$ ) between the rhythms and lactate levels in predicting 1-month survival. The ROC curve showed area under the curve of $0.75(95 \% \mathrm{Cl} 0.70-0.80)$ in patients with nonshockable rhythm and of $0.53(95 \% \mathrm{Cl} 0.43-0.62)$ in patients with shockable rhythm.

\section{Discussion}

\section{Summary}

Using a Japanese large-scale prospective registry of OHCA, we demonstrated that the increased serum lactate level during CPR was significantly associated with decreased 1-month survival among OHCA patients. Especially, the relationship between high lactate levels during CPR and decreased one-month survival was observed in patients with non-shockable initial rhythm, but not in patients with shockable rhythm. Lactate levels during CPR may serve as one of the early prognostic biomarkers of OHCA and facilitate the decision-making process of providing intensive care to improve outcomes after OHCA.

\section{Comparison with Previous Studies}

Previous studies on serum lactate levels focused mainly on OHCA patients who achieved ROSC. Lee and colleagues, in South Korea, reported that high lactate levels within 1 hour after ROSC were related to hospital mortality and poor neurological outcomes in OHCA patients who underwent therapeutic hypothermia. ${ }^{15}$ Moreover, Shinozaki and colleagues, in Japan, revealed that lactate and blood ammonia levels within 15 minutes of hospital arrival were independent prognostic factors, and when both biomarker levels were over the threshold, the positive predictive value for poor outcomes was nearly $100 \% .{ }^{16}$ Regarding serum lactate levels before ROSC, Sarıaydın and colleagues, in Turkey, found that initial lactate levels of OHCA patients without ROSC before hospital arrival were not associated with 24-hour survival, but the number of patients was small. ${ }^{30}$ Importantly, our large-scale registry enabled us to demonstrate the dose-dependent association between serum lactate levels during CPR and 1-month survival among OHCA patients by multivariable logistic regression analysis.

\section{Interpretation of the Results and Possible Implications}

Lactate levels are considered to be predictive markers of hemodynamic indicators in critical illness. ${ }^{8-10}$ Cardiac arrest causes systemic tissue hypoxia, consequently resulting in the production of excessive lactate levels in anaerobic metabolism. ${ }^{8-10}$ Even with $^{-10}$ chest compressions during cardiac arrest, systemic oxygen delivery is insufficient, ${ }^{32,33}$ and lactate levels increase owing to the hypoperfusion of vital organs. Therefore, lactate level could be a marker of circulatory failure and prognostic marker of cardiac arrest.

Furthermore, even under aerobic conditions, lactate level may be elevated by many factors, e.g., stress hyperlactatemia, ${ }^{34,35}$ systemic inflammatory response, ${ }^{34,36}$ myocardial stunning, ${ }^{10}$ and mitochondrial dysfunction. ${ }^{10,37}$ These multiple factors may be associated with the critical condition of OHCA because cardiac arrest is a highly heterogeneous entity. Whatever the cause, elevated lactate level might be a prognostic marker of poor outcomes in OHCA patients.

Serum lactate level before ROSC should be a more useful prognostic predictor of cardiac arrest than that after ROSC. In the clinical settings of OHCA patients during CPR, physicians need to decide whether to initiate advanced interventions such as TTM and ECPR. Furthermore, the clinical decision to terminate resuscitation must be made during CPR. Serum lactate levels can be immediately and objectively measured even during CPR, enabling physicians to understand OHCA patients' conditions even if their prehospitalization 
information is unknown. For this reason, lactate levels during CPR can help clinicians' decide whether to proceed to advanced interventions or to stop CPR during resuscitation efforts for OHCA patients.

Interestingly, our subgroup analysis demonstrated no relationship between lactate levels during CPR and survival among OHCA patients with initial shockable rhythm. On the other hand, in patients with non-shockable rhythm, the receiver operating characteristic of lactate level was 0.75 , and the prognostic value was relatively high. In patients with shockable rhythm, some blood flow is maintained ${ }^{38}$ and the tissue oxygen delivery might be relatively maintained even when the lactate level rises under aerobic conditions. Further research is required to clarify the mechanisms underlying the role of lactate levels. Thus, early prognostic stratification of OHCA patients should not be based on a single factor, and serum lactate level should be used as one of the predictors in conjunction with others in a multidisciplinary assessment.

\section{Limitations}

This study has several inherent limitations. First, because this was an observational study, the protocols, such as timing of blood work, were not strictly defined in each hospital. In addition, we could not determine the blood collection sites during CPR or whether arterial or venous blood was collected. However, there was no remarkable difference in lactate levels between collection sites or between blood samples from the artery and vein in a previous study. ${ }^{39}$ Second, this registry did not obtain detailed information about each patient, their past medical history, medications, or comorbidities. For example, liver failure as comorbidity, medication, fluid infusion, and vasopressor use during CPR might affect lactate dynamics. If patients with high lactate levels had these conditions, the results would have tended toward poor outcomes. Third, blood parameters other than lactate levels were excluded from our final analyses because they were measured simultaneously with blood gas data. As serum lactate level would be influenced by other blood data, it would be beneficial to investigate the effect of combining other biomarkers and establish a prognostic prediction model of OHCA with multiple factors. Finally, unmeasured confounding factors may have influenced the association between the lactate levels during CPR and OHCA outcomes.

\section{Conclusion}

Using the large multicenter prospective registry of OHCA, we demonstrated that high serum lactate levels during CPR were associated with poor 1-month survival, especially in patients with non-shockable rhythm, suggesting the role of serum lactate level as a prognostic marker of outcomes for OHCA patients before ROSC.

\section{Abbreviations}

CCMC: critical care medical center; CPC: Cerebral Performance Category; CRITICAL: Comprehensive Registry of Intensive Care for OHCA Survival; ECPR: extracorporeal cardiopulmonary resuscitation; EMS: emergency-medical-services; FDMA: Fire and Disaster Management Agency; OHCA: out-of-hospital cardiac arrest; OR: odds ratios; Cl: confidence intervals; ROC: receiver operating characteristics; ROSC: return of spontaneous circulation; TTM: target temperature management.

\section{Declarations}

\section{Ethics approval and consent to participate}

The Ethics Committee of Kyoto University Graduate School of Medicine and participating institution approved this registry study. The written informed consent requirement was waived.

\section{Consent for publication}

Not applicable

\section{Availability of data and materials}

The dataset supporting the conclusions of this article is available from the corresponding author on reasonable request.

\section{Competing interests}


All the authors declare that they have no potential conflict of interest.

\section{Funding}

This study was supported by a scientific research grant from the Ministry of Education, Culture, Sports, Science and Technology of Japan (16K09034 and 19K09393).

\section{Author's contributions}

NN: Conception, Design of the work, Interpretation of data, Formal analysis, Writing -Original Draft, DK, Jl: Conception, Design of the work, Interpretation of data, Writing - Review \& Editing, TIrisawa, TY, KY, CP, TN, TIshibe, YY, TKiguchi, MK, TInoue, YH, TSogabe, TMorooka, HS, KS, FN, TMatsuyama: Project administration, Data Resource, Data Curation, Supervision, YO, SM, AH, SY, SK: Data Resource, Data Curation, Interpretation of data, TS: Project administration, Supervision, Takashi K: Methodology, Supervision, Tetsuhisa K: Methodology, Data Curation, Supervision, Project administration, Writing - Review \& Editing, Funding acquisition, Taku I: Methodology, Writing - Review \& Editing, Supervision, Project administration, Funding acquisition. All authors criticized intellectual contents and approved the final manuscript.

\section{Acknowledgments}

We are deeply indebted to all the members of the CRITICAL study group for their contribution. We are also deeply grateful to all of the EMS personnel for collecting Utstein data and to Ms. Ikuko Nakamura for supporting the CRITICAL study.

\section{Author details}

${ }^{1}$ Department of Preventive Services, Kyoto University School of Public Health, Kyoto, Japan. ${ }^{2}$ Kyoto University Health Services, Kyoto, Japan. ${ }^{3}$ Department of Medicine, Okinawa Prefectural Yaeyama Hospital, Ishigaki, Japan. ${ }^{4}$ Department of Traumatology and Acute Critical Medicine, Osaka University Graduate School of Medicine, Suita, Japan. ${ }^{5}$ Emergency and Critical Care Medical Center, Osaka Police Hospital, Osaka, Japan. ${ }^{6}$ Department of Emergency and Critical Care Medicine, Kansai Medical University, Takii Hospital, Moriguchi, Japan. ${ }^{7}$ Department of Emergency Medicine, Tane General Hospital, Osaka, Japan. ${ }^{8}$ Department of Critical Care Medicine, Osaka City University, Osaka, Japan. ${ }^{9}$ Department of Emergency and Critical Care Medicine, Kindai University Faculty of Medicine, Osaka-Sayama, Japan. ${ }^{10}$ Osaka Mishima Emergency Critical Care Center, Takatsuki, Japan. ${ }^{11}$ Critical Care and Trauma Center, Osaka General Medical Center, Osaka, Japan. ${ }^{12}$ Osaka Prefectural Nakakawachi Medical Center of Acute Medicine, Higashi-Osaka, Japan.

${ }^{13}$ Senshu Trauma and Critical Care Center, Osaka, Japan. ${ }^{14}$ Senri Critical Care Medical Center, Saiseikai Senri Hospital, Suita, Japan.

${ }^{15}$ Traumatology and Critical Care Medical Center, National Hospital Organization Osaka National Hospital, Osaka, Japan.

${ }^{16}$ Emergency and Critical Care Medical Center, Osaka City General Hospital, Osaka, Japan. ${ }^{17}$ Department of Pediatrics, Osaka Red Cross Hospital, Osaka, Japan. ${ }^{18}$ Emergency and Critical Care Medical Center, Kishiwada Tokushukai Hospital, Osaka, Japan.

${ }^{19}$ Department of Emergency and Critical Care Medicine, Kansai Medical University, Hirakata, Osaka, Japan. ${ }^{20}$ Department of Emergency Medicine, Kyoto Prefectural University of Medicine, Kyoto, Japan. ${ }^{21}$ Division of Environmental Medicine and Population Sciences, Department of Social and Environmental Medicine, Graduate School of Medicine, Osaka University, Osaka, Japan. ${ }^{22}$ Public Health, Department of Social and Environmental Medicine, Osaka University Graduate School of Medicine, Osaka, Japan

\section{References}

1. Benjamin EJ, Blaha MJ, Chiuve SE, Cushman M, Das SR, Deo R, et al. Heart Disease and Stroke Statistics-2017 Update: A Report From the American Heart Association. Circulation. 2017;135(10):e146-e603.

2. Perkins GD, Handley AJ, Koster RW, Castren M, Smyth MA, Olasveengen T, et al. European Resuscitation Council Guidelines for Resuscitation 2015: Section 2. Adult basic life support and automated external defibrillation. Resuscitation. 2015;95:81-99.

3. Kitamura T, Kiyohara K, Sakai T, Matsuyama T, Hatakeyama T, Shimamoto T, et al. Public-Access Defibrillation and Out-ofHospital Cardiac Arrest in Japan. N Engl J Med. 2016;375(17):1649-59.

4. Ouweneel DM, Schotborgh JV, Limpens J, Sjauw KD, Engstrom AE, Lagrand WK, et al. Extracorporeal life support during cardiac arrest and cardiogenic shock: a systematic review and meta-analysis. Intensive Care Med. 2016;42(12):1922-34. 
5. Nordberg P, Taccone FS, Truhlar A, Forsberg S, Hollenberg J, Jonsson M, et al. Effect of Trans-Nasal Evaporative Intra-arrest Cooling on Functional Neurologic Outcome in Out-of-Hospital Cardiac Arrest: The PRINCESS Randomized Clinical Trial. Jama. 2019;321(17):1677-85.

6. Bossaert LL, Perkins GD, Askitopoulou H, Raffay VI, Greif R, Haywood KL, et al. European Resuscitation Council Guidelines for Resuscitation 2015: Section 11. The ethics of resuscitation and end-of-life decisions. Resuscitation. 2015;95:302-11.

7. Mancini ME, Diekema DS, Hoadley TA, Kadlec KD, Leveille MH, McGowan JE, et al. Part 3: Ethical Issues: 2015 American Heart Association Guidelines Update for Cardiopulmonary Resuscitation and Emergency Cardiovascular Care. Circulation. 2015;132(18 Suppl 2):S383-96.

8. Kraut JA, Madias NE. Lactic acidosis. N Engl J Med. 2014;371(24):2309-19.

9. Reddy AJ, Lam SW, Bauer SR, Guzman JA. Lactic acidosis: Clinical implications and management strategies. Cleve Clin J Med. 2015;82(9):615-24.

10. Andersen LW, Mackenhauer J, Roberts JC, Berg KM, Cocchi MN, Donnino MW. Etiology and therapeutic approach to elevated lactate levels. Mayo Clin Proc. 2013;88(10):1127-40.

11. Haas SA, Lange T, Saugel B, Petzoldt M, Fuhrmann V, Metschke M, et al. Severe hyperlactatemia, lactate clearance and mortality in unselected critically ill patients. Intensive Care Med. 2016;42(2):202-10.

12. Nichol AD, Egi M, Pettila V, Bellomo R, French C, Hart G, et al. Relative hyperlactatemia and hospital mortality in critically ill patients: a retrospective multi-centre study. Crit Care. 2010;14(1):R25.

13. Davis JW, Dirks RC, Kaups KL, Tran P. Base deficit is superior to lactate in trauma. Am J Surg. 2018;215(4):682-5.

14. Kamolz LP, Andel H, Schramm W, Meissl G, Herndon DN, Frey M. Lactate: early predictor of morbidity and mortality in patients with severe burns. Burns. 2005;31(8):986-90.

15. Lee DH, Cho IS, Lee SH, Min YI, Min JH, Kim SH, et al. Correlation between initial serum levels of lactate after return of spontaneous circulation and survival and neurological outcomes in patients who undergo therapeutic hypothermia after cardiac arrest. Resuscitation. 2015;88:143-9.

16. Shinozaki K, Oda S, Sadahiro T, Nakamura M, Hirayama Y, Watanabe E, et al. Blood ammonia and lactate levels on hospital arrival as a predictive biomarker in patients with out-of-hospital cardiac arrest. Resuscitation. 2011;82(4):404-9.

17. Starodub R, Abella BS, Grossestreuer AV, Shofer FS, Perman SM, Leary M, et al. Association of serum lactate and survival outcomes in patients undergoing therapeutic hypothermia after cardiac arrest. Resuscitation. 2013;84(8):1078-82.

18. During J, Dankiewicz J, Cronberg T, Hassager C, Hovdenes J, Kjaergaard J, et al. Lactate, lactate clearance and outcome after cardiac arrest: A post-hoc analysis of the TTM-Trial. Acta Anaesthesiol Scand. 2018;62(10):1436-42.

19. Lee TR, Kang MJ, Cha WC, Shin TG, Sim MS, Jo IJ, et al. Better lactate clearance associated with good neurologic outcome in survivors who treated with therapeutic hypothermia after out-of-hospital cardiac arrest. Crit Care. 2013;17(5):R260.

20. Yamada T, Kitamura T, Hayakawa K, Yoshiya K, Irisawa T, Abe Y, et al. Rationale, design, and profile of Comprehensive Registry of In-Hospital Intensive Care for OHCA Survival (CRITICAL) study in Osaka, Japan. J Intensive Care. 2016;4:10.

21. Osaka Prefectural Government. 2015 report on medical institutions in Osaka Prefecture (in Japanese). (Accessed 27 May 2020 , at http://www.pref.osaka.lg.jp/kenisomu/syuyoufukusidate/hoken1-0.html.)

22. Kajino K, Iwami T, Daya M, Nishiuchi T, Hayashi Y, Kitamura T, et al. Impact of transport to critical care medical centers on outcomes after out-of-hospital cardiac arrest. Resuscitation. 2010;81(5):549-54.

23. Japan Resuscitation Council. 2015 Japanese Guidelines for Emergency Care and Cardiopulmonary Resuscitation. Tokyo: IgakuShoin; 2016 (in Japanese).

24. Iwami T, Kawamura T, Hiraide A, Berg RA, Hayashi Y, Nishiuchi T, et al. Effectiveness of bystander-initiated cardiac-only resuscitation for patients with out-of-hospital cardiac arrest. Circulation. 2007;116(25):2900-7.

25. Iwami T, Nichol G, Hiraide A, Hayashi Y, Nishiuchi T, Kajino K, et al. Continuous improvements in "chain of survival" increased survival after out-of-hospital cardiac arrests: a large-scale population-based study. Circulation. 2009;119(5):728-34.

26. Kitamura T, Iwami T, Kawamura T, Nagao K, Tanaka H, Hiraide A. Nationwide public-access defibrillation in Japan. N Engl J Med. 2010;362(11):994-1004.

27. Cummins RO, Chamberlain DA, Abramson NS, Allen M, Baskett PJ, Becker $L$, et al. Recommended guidelines for uniform reporting of data from out-of-hospital cardiac arrest: the Utstein Style. A statement for health professionals from a task force of the 
American Heart Association, the European Resuscitation Council, the Heart and Stroke Foundation of Canada, and the Australian Resuscitation Council. Circulation. 1991;84(2):960-75.

28. Becker LB, Aufderheide TP, Geocadin RG, Callaway CW, Lazar RM, Donnino MW, et al. Primary outcomes for resuscitation science studies: a consensus statement from the American Heart Association. Circulation. 2011;124(19):2158-77.

29. Kanda Y. Investigation of the freely available easy-to-use software 'EZR' for medical statistics. Bone Marrow Transplant. 2013;48(3):452-8.

30. Sariaydin T, Corbacioglu SK, Cevik Y, Emektar E. Effect of initial lactate level on short-term survival in patients with out-ofhospital cardiac arrest. Turk J Emerg Med. 2017;17(4):123-7.

31. Starodub R, Abella BS, Grossestreuer AV, Shofer FS, Perman SM, Leary M, et al. Association of serum lactate and survival outcomes in patients undergoing therapeutic hypothermia after cardiac arrest. Resuscitation. 2013;84(8):1078-82.

32. Cavus E, Bein B, Dorges V, Stadlbauer KH, Wenzel V, Steinfath M, et al. Brain tissue oxygen pressure and cerebral metabolism in an animal model of cardiac arrest and cardiopulmonary resuscitation. Resuscitation. 2006;71(1):97-106.

33. Magliocca A, Olivari D, De Giorgio D, Zani D, Manfredi M, Boccardo A, et al. LUCAS Versus Manual Chest Compression During Ambulance Transport: A Hemodynamic Study in a Porcine Model of Cardiac Arrest. J Am Heart Assoc. 2019;8(1):e011189.

34. Bakker J, Nijsten MW, Jansen TC. Clinical use of lactate monitoring in critically ill patients. Ann Intensive Care. 2013;3(1):12.

35. Garcia-Alvarez M, Marik P, Bellomo R. Stress hyperlactataemia: present understanding and controversy. Lancet Diabetes Endocrinol. 2014;2(4):339-47.

36. Garcia-Alvarez M, Marik P, Bellomo R. Sepsis-associated hyperlactatemia. Crit Care. 2014;18(5):503.

37. Xu W, Fu Y, Jiang L, Yang Z, Wang Y, Tang W, et al. Cardiopulmonary resuscitation ameliorates myocardial mitochondrial dysfunction in a cardiac arrest rat model. Am J Emerg Med. 2020;38(1):65-72.

38. Ristagno G, Tang W, Sun S, Weil MH. Spontaneous gasping produces carotid blood flow during untreated cardiac arrest. Resuscitation. 2007;75(2):366-71.

39. Ralston SH, Voorhees WD, Showen L, Schmitz P, Kougias C, Tacker WA. Venous and arterial blood gases during and after cardiopulmonary resuscitation in dogs. Am J Emerg Med. 1985;3(2):132-6.

\section{Tables}


Table 1. Characteristics after OHCA patients by serum lactate level measured during cardiac arrest at hospital arrival

\begin{tabular}{|c|c|c|c|c|c|c|}
\hline \multirow[t]{2}{*}{ All Patients } & \multirow[t]{2}{*}{ Missing } & Quartile 1 & Quartile 2 & Quartile 3 & Quartile 4 & \\
\hline & & $\begin{array}{c}(\leq 10.6 \\
\mathrm{mmol} / \mathrm{L})\end{array}$ & $\begin{array}{l}\text { (10.6-14.1 } \\
\text { mmol/L) }\end{array}$ & $\begin{array}{l}(14.1-18 \\
\mathrm{mmol} / \mathrm{L})\end{array}$ & (>18 mmol/L) & $\begin{array}{l}P \\
\text { Values* }\end{array}$ \\
\hline$(n=4978)$ & & $(n=1245)$ & $(n=1245)$ & $(n=1328)$ & $(n=1160)$ & \\
\hline
\end{tabular}

\section{Patient}

characteristics

\begin{tabular}{|c|c|c|c|c|c|c|c|c|c|c|c|c|c|}
\hline $\begin{array}{l}\text { Age, median } \\
{[\text { IQR] }}\end{array}$ & 75 & $\begin{array}{l}(64- \\
82)\end{array}$ & 0 & $(0.0)$ & 77 & $\begin{array}{l}(67- \\
83)\end{array}$ & 77 & $\begin{array}{l}(66- \\
84)\end{array}$ & 75 & $\begin{array}{l}(65- \\
83)\end{array}$ & 72 & $\begin{array}{l}(57- \\
81)\end{array}$ & $<0.001$ \\
\hline Sex, male, n & 3052 & (61.3) & 0 & $(0.0)$ & 750 & (60.2) & 777 & (62.4) & 817 & (61.5) & 709 & (61.1) & 0.735 \\
\hline
\end{tabular}
(\%)

$\begin{array}{llllllllllllll}\begin{array}{c}\text { Witnessed } \\ \text { arrest, } \mathrm{n}(\%)\end{array} & 2137 & (43.0) & 0 & (0.0) & 767 & (61.6) & 615 & (49.4) & 479 & (36.1) & 276 & (23.8) & <0.001 \\ \begin{array}{c}\text { Cardiac } \\ \text { etiology of } \\ \text { arrest, } \mathrm{n}(\%)\end{array} & 3888 & (78.1) & 0 & (0.0) & 934 & (75.0) & 955 & (76.7) & 1062 & (80.0) & 937 & (80.8) & 0.001 \\ \end{array}$

\section{Pre-hospital \\ information}

\begin{tabular}{|c|c|c|c|c|c|c|c|c|c|c|c|c|c|}
\hline $\begin{array}{l}\text { Bystander } \\
\text { CPR, n (\%) }\end{array}$ & 2079 & (41.8) & 0 & $(0.0)$ & 487 & (39.1) & 525 & (42.2) & 539 & $(40.6)$ & 528 & $(45.5)$ & 0.011 \\
\hline $\begin{array}{l}\text { Shock by } \\
\text { public-access } \\
\text { AEDs, n (\%) }\end{array}$ & 35 & $(0.7)$ & 0 & $(0.0)$ & 3 & $(0.2)$ & 17 & (1.4) & 14 & $(1.1)$ & 1 & $(0.1)$ & $<0.001$ \\
\hline $\begin{array}{l}\text { Shockable } \\
\text { rhythm at the } \\
\text { scene, n (\%) }\end{array}$ & 336 & $(6.8)$ & 0 & $(0.0)$ & 137 & $(11.0)$ & 100 & $(8.0)$ & 59 & $(4.4)$ & 40 & $(3.4)$ & $<0.001$ \\
\hline \begin{tabular}{l}
\multicolumn{1}{c}{ Adrenaline } \\
administration \\
by EMS, n (\%)
\end{tabular} & 820 & (16.5) & 0 & $(0.0)$ & 258 & $(20.7)$ & 212 & (17.0) & 227 & $(17.1)$ & 123 & (10.6) & $<0.001$ \\
\hline $\begin{array}{l}\quad \text { Advanced } \\
\text { airway } \\
\text { management, } \\
\text { n (\%) }\end{array}$ & 2151 & $(43.2)$ & 0 & $(0.0)$ & 531 & $(42.7)$ & 544 & $(43.7)$ & 593 & $(44.7)$ & 483 & $(41.6)$ & 0.462 \\
\hline
\end{tabular}
$\begin{array}{lllllllllllll}\text { Time from } & 8 & (7-10) & 6 & (0.2) & 8 & (6-10) & 8 & (7-10) & 8 & (7-10) & 8 & (7-10)\end{array}$ call to EMS
contact,
median (IQR),
$\min$

\begin{tabular}{|c|c|c|c|c|c|c|c|c|c|c|c|c|}
\hline $\begin{array}{l}\text { Time from } \\
\text { call to }\end{array}$ & 32 & $\begin{array}{l}(27- \\
40)\end{array}$ & 46 & $(0.9)$ & 31 & $\begin{array}{l}(26- \\
39)\end{array}$ & 32 & $\begin{array}{l}(26- \\
39)\end{array}$ & 33 & $\begin{array}{l}(27- \\
40)\end{array}$ & 34 & $\begin{array}{l}(28- \\
42)\end{array}$ \\
\hline
\end{tabular}

hospital

arrival,

median (IQR),

min

In-hospital

information

\begin{tabular}{|c|c|c|c|c|c|c|c|c|c|c|c|c|c|}
\hline $\begin{array}{l}\text { Shockable } \\
\text { rhythm on } \\
\text { hospital } \\
\text { arrival, n (\%) }\end{array}$ & 153 & (3.1) & 0 & $(0.0)$ & 56 & (4.5) & 51 & (4.1) & 30 & (2.3) & 16 & $(1.4)$ & $<0.001$ \\
\hline $\begin{array}{l}\text { Adrenaline } \\
\text { administration } \\
\text { at hospital, } n \\
(\%)\end{array}$ & 4599 & (92.4) & 10 & $(0.2)$ & 1150 & (92.6) & 1151 & (92.7) & 1239 & (93.5) & 1059 & (91.3) & 0.211 \\
\hline
\end{tabular}




\begin{tabular}{|c|c|c|c|c|c|c|c|c|c|c|c|c|c|}
\hline $\begin{array}{l}\text { Coronary } \\
\text { angiography, } \\
\text { n (\%) }\end{array}$ & 80 & (1.6) & 0 & $(0.0)$ & 28 & (2.2) & 28 & (2.2) & 21 & (1.6) & 3 & (0.3) & $<0.001$ \\
\hline $\begin{array}{l}\text { Target } \\
\text { temperature } \\
\text { management, } \\
\mathrm{n}(\%)\end{array}$ & 116 & (2.3) & 0 & $(0.0)$ & 43 & (3.7) & 42 & (3.4) & 24 & (1.8) & 7 & (0.6) & $<0.001$ \\
\hline $\begin{array}{l}\text { Time from } \\
\text { hospital } \\
\text { arrival to } \\
\text { lactate } \\
\text { measurement, } \\
\text { median (IQR), } \\
\text { min }\end{array}$ & 5 & $(3-10)$ & 0 & $(0.0)$ & 5 & $(2-9)$ & 5 & $(2-10)$ & 5 & $(3-10)$ & 6 & $(3-12)$ & $<0.001$ \\
\hline \multicolumn{14}{|c|}{$\begin{array}{l}\text { OHCA, out-of-hospital cardiac arrest; ROSC, return of spontaneous circulation; AED, automated external defibrillator; CPR, } \\
\text { cardiopulmonary resuscitation; }\end{array}$} \\
\hline \multicolumn{14}{|l|}{$\begin{array}{l}\text { EMS, } \\
\text { emergency } \\
\text { medical } \\
\text { services; IQR, } \\
\text { Inter quartile } \\
\text { range }\end{array}$} \\
\hline
\end{tabular}


Table 2. Outcomes after OHCA by serum lactate level measured during cardiac arrest at hospital arrival

\begin{tabular}{|c|c|c|c|c|c|}
\hline & Quartile1 & Quartile2 & Quartile3 & Quartile4 & \\
\hline & $\begin{array}{l}(\leq 10.6 \\
\mathrm{mmol} / \mathrm{L})\end{array}$ & $\begin{array}{l}(10.6-14.1 \\
\mathrm{mmol} / \mathrm{L})\end{array}$ & $\begin{array}{l}(14.1-18 \\
\mathrm{mmol} / \mathrm{L})\end{array}$ & $(>18 \mathrm{mmol} / \mathrm{L})$ & $\begin{array}{l}P \text { for } \\
\text { trend }\end{array}$ \\
\hline & $n=1245$ & $n=1245$ & $n=1328$ & $n=1160$ & \\
\hline \multicolumn{6}{|l|}{ Primary outcome } \\
\hline One-month survival (\%) & $53(4.3)$ & $31(2.5)$ & $14(1.1)$ & $6(0.5)$ & $<0.001$ \\
\hline Crude OR $(95 \% \mathrm{Cl})$ & Reference & $\begin{array}{l}0.57(0.37 \text { to } \\
0.90)\end{array}$ & $\begin{array}{l}0.24(0.13 \text { to } \\
0.43)\end{array}$ & $\begin{array}{l}0.12(0.050 \text { to } \\
0.27)\end{array}$ & \\
\hline Adjusted OR $(95 \% \mathrm{Cl})^{*}$ & Reference & $\begin{array}{l}0.66(0.41 \text { to } \\
1.05)\end{array}$ & $\begin{array}{l}0.36(0.19 \text { to } \\
0.66)\end{array}$ & $\begin{array}{l}0.21(0.086 \text { to } \\
0.50)\end{array}$ & \\
\hline \multicolumn{6}{|l|}{ Secondary outcome } \\
\hline $\begin{array}{l}\text { Any ROSC after measuring } \\
\text { lactate (\%) }\end{array}$ & 397 (31.9) & $379(30.4)$ & $305(23.0)$ & $143(12.3)$ & $<0.001$ \\
\hline Crude OR (95\% Cl) & Reference & $\begin{array}{l}0.93(0.79 \text { to } \\
1.11)\end{array}$ & $\begin{array}{l}0.64(0.54 \text { to } \\
0.76)\end{array}$ & $\begin{array}{l}0.30(0.24 \text { to } \\
0.37)\end{array}$ & \\
\hline Adjusted OR $(95 \% \mathrm{Cl})^{\star}$ & Reference & $\begin{array}{l}1.06(0.89 \text { to } \\
1.27)\end{array}$ & $\begin{array}{l}0.82(0.68 \text { to } \\
0.98)\end{array}$ & $\begin{array}{l}0.43(0.34 \text { to } \\
0.54)\end{array}$ & \\
\hline $\begin{array}{l}\text { Favorable neurological outcome } \\
\text { (\%) }\end{array}$ & $11(0.9)$ & $8(0.6)$ & $7(0.5)$ & $3(0.3)$ & 0.048 \\
\hline Crude OR (95\% Cl) & Reference & $\begin{array}{l}0.73(0.29 \text { to } \\
1.81)\end{array}$ & $\begin{array}{l}0.59(0.23 \text { to } \\
1.54)\end{array}$ & $\begin{array}{l}0.29(0.081 \text { to } \\
1.05)\end{array}$ & \\
\hline Adjusted OR & - & - & - & - & \\
\hline \multicolumn{6}{|c|}{$\begin{array}{l}\text { *Adjusted for age, sex, bystander witness, bystander CPR, first documented rhythm at the scene, prehospital advanced airway } \\
\text { management, time from EMS call to hospital arrival, and prehospital adrenaline administration }\end{array}$} \\
\hline \multicolumn{6}{|c|}{ OHCA, out-of-hospital cardiac arrest; ROSC, return of spontaneous circulation; OR, odds ratio; $\mathrm{Cl}$, confidence interval } \\
\hline
\end{tabular}


Table 3. One-month survival after OHCA by serum lactate level measured during cardiac arrest at hospital arrival according to first documented rhythm

\begin{tabular}{|c|c|c|c|c|c|c|}
\hline & Quartile1 & Quartile2 & Quartile3 & Quartile4 & $\begin{array}{l}\text { P for } \\
\text { trend }\end{array}$ & $\begin{array}{l}\text { P for } \\
\text { interaction* }\end{array}$ \\
\hline & $\begin{array}{l}(\leq 10.6 \\
\mathrm{mmol} / \mathrm{L})\end{array}$ & $\begin{array}{l}(10.6-14.1 \\
\mathrm{mmol} / \mathrm{L})\end{array}$ & $\begin{array}{l}(14.1-18 \\
\mathrm{mmol} / \mathrm{L})\end{array}$ & $\begin{array}{l}(>18 \\
\mathrm{mmol} / \mathrm{L})\end{array}$ & & \\
\hline Shockable rhythm $(n=336)$ & & & & & & $<0.001$ \\
\hline $\mathrm{n} / \mathrm{N}(\%)$ & 12/137 (8.8) & 12/100 (12.0) & 8/59 (13.6) & $3 / 40(7.5)$ & 0.76 & \\
\hline Crude OR (95\%Cl) & Reference & $1.42(0.61$ to 3.31$)$ & $\begin{array}{l}1.63(0.63 \\
\text { to } 4.23)\end{array}$ & $\begin{array}{l}0.84(0.23 \text { to } \\
3.15)\end{array}$ & & \\
\hline \multicolumn{7}{|l|}{$\begin{array}{l}\text { Non shockable ihythm }(n= \\
\text { 4642) }\end{array}$} \\
\hline $\mathrm{n} / \mathrm{N}(\%)$ & 41/1097 (3.7) & 19/1151 (1.7) & $\begin{array}{l}6 / 1274 \\
(0.5)\end{array}$ & $3 / 1120(0.3)$ & $<0.001$ & \\
\hline Crude OR $(95 \% \mathrm{Cl})$ & Reference & $0.43(0.25$ to 0.75$)$ & $\begin{array}{l}0.12(0.052 \\
\text { to } 0.29)\end{array}$ & $\begin{array}{l}0.069(0.021 \\
\text { to } 0.22)\end{array}$ & & \\
\hline \multicolumn{7}{|c|}{$\begin{array}{l}\text { OHCA, out-of-hospital cardiac arrest; ROSC, return of spontaneous circulation; OR, odds ratio; Cl, } \\
\text { confidence interval }\end{array}$} \\
\hline \multicolumn{3}{|c|}{$\begin{array}{l}\text { *P for interaction was calculated between serum lactate level and first } \\
\text { documented rhthm in one-month survival }\end{array}$} & \multicolumn{3}{|c|}{$\begin{array}{l}\text { rhythm in one- } \\
\text { month survival }\end{array}$} & \\
\hline
\end{tabular}

\section{Figures}


Out-of-hospital cardiac arrest registered in the CRITICAL study between 2013 and 2017

$$
\mathrm{n}=11,960
$$

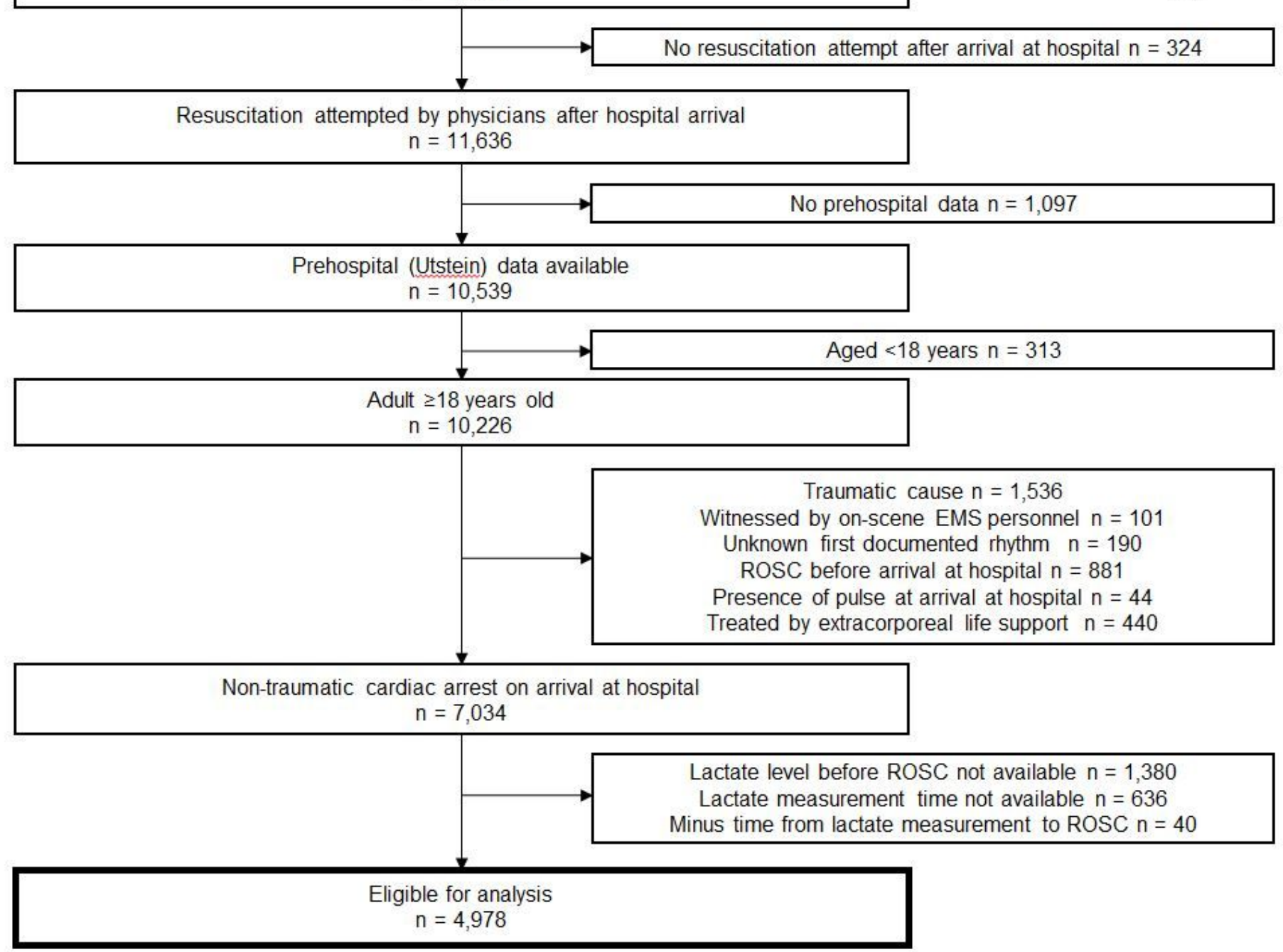

\section{Figure 1}

Overview of out-of-hospital cardiac arrests from 2013 to 2017 in the CRITICAL study EMS $=$ emergency medical service, OHCA $=$ outof-hospital cardiac arrest, ROSC = return of spontaneous circulation 